\title{
Centralidade na Avaliação e Educação Customizada: \\ o fim da escola como espaço para transmissão de uma "cultura comum"? ?
}

\author{
Renata Porcher Scherer ${ }^{2}$
}

\begin{abstract}
Resumo:
0 presente artigo tem como objetivo examinar e problematizar os significados acerca dos processos de avaliação escolar que, contemporaneamente, são produzidos no interior do discurso pedagógico e os modos pelos quais são visibilizados por revistas brasileiras, contribuindo para a produção de uma educação cada vez mais individual e customizada. Para análise do material empírico toma-se como pano de fundo os estudos sociológicos de Zygmunt Bauman sobre os processos de individualização e responsabilização dos indivíduos dentro de uma racionalidade neoliberal. Mostra-se que a proliferação de mecanismos para avaliação dos estudantes atua, de um lado, produzindo maior controle e intensificação do trabalho docente e, de outro, opera fortalecendo a constituição de uma educação cada vez mais customizada diminuindo as possibilidades para que a escola atue como um espaço de transmissão de uma "cultura comum".
\end{abstract}

Palavras-chave: Avaliação. Trabalho docente. Individualização. Educação Básica.

\section{CENTRALITY IN EVALUATION AND CUSTOMIZED EDUCATION: the end of the school as a space for transmission of a "common culture"?}

\begin{abstract}
:
This article aims to examine and problematize the meanings about the processes of school evaluation that are produced simultaneously within the pedagogical discourse and the ways in which they are visualized by Brazilian magazines, contributing to the production of an
\end{abstract}

\footnotetext{
1 Este trabalho apresenta parte dos resultados da dissertação de Mestrado da autora, intitulada "Cada um aprende de um jeito": das adaptações às flexibilizações curriculares (SCHERER, 2014), defendida na Universidade do Vale do Rio dos Sinos, com apoio financeiro do CNPq e realizada sob a orientação da professora doutora Maria Cláudia Dal'Igna.

2 Doutoranda em Educação. Universidade do Vale do Rio dos Sinos - Unisinos. renata_ps3@ yahoo. com.br
}

\begin{tabular}{l|l|l|l|l}
\hline Editora Unijuí & Ano 32 & $\mathrm{n}^{\circ} 102$ & Maio/Ago. 2017 & P. 118-144
\end{tabular}


education every time more and more individual and customized. For the analysis of the empirical material, Zygmunt Bauman's sociological studies on the processes of individualization and accountability of individuals within a neoliberal rationality are taken as background. It is shown that the proliferation of mechanisms for student evaluation acts on the one hand producing greater control and intensification of teaching work and on the other hand it works by strengthening the constitution of an increasingly customized education, reducing the possibilities for the school to act as a space for transmission of a "common culture".

Keywords: Evaluation. Teaching work. Individualization. Basic Education. 
[...] Se a escola "homogênea" foi construída historicamente, a escola da heterogeneidade e da diversidade também o será (PÁTIO, 2010, p. 12). ${ }^{3}$

A epígrafe escolhida para abrir este artigo parece-nos emblemática para descrever os investimentos que têm sido realizados contemporaneamente para constituição de uma "educação customizada" (PÁTIO, 2010). Ao investigarmos os sentidos que têm sido produzidos sobre os processos de avaliação em revistas pedagógicas brasileiras, mostramos que estes parecem investir cada vez mais em avaliações personalizadas, contribuindo para o fortalecimento de uma educação customizada e para o enfraquecimento da escola como espaço onde se transmite uma "cultura comum" (DUSSEL, 2009).

A produção de uma educação customizada foi examinada por Silva (2014) que, ao realizar uma pesquisa tendo como base os currículos escolares para o Ensino Médio no sul do país, mapeia a constituição de "dispositivos de customização curricular" (SILVA, 2014). De acordo com o autor, nesse processo os próprios estudantes são acionados e responsabilizados ao serem chamados para definir seus percursos formativos a partir de seus interesses e suas condições socioculturais.

Tomando como argumento central a hipótese de que a customização curricular e, no caso deste artigo, a customização dos processos de avaliação produzem a responsabilização dos estudantes ao chamá-los para definir seus percursos formativos, o presente texto tomará como pano de fundo as discussões sociológicas contemporâneas de Zygmunt Bauman sobre os processos de individualização e responsabilização dos indivíduos, nos quais, nas palavras do sociólogo, "a individualização é um destino, não uma escolha: na terra da liberdade individual de escolha, a opção de escapar à individualização e de se negar a participar do jogo individualizante não faz parte, de maneira alguma, da agenda" (BAUMAN, 2008, p. 64).

\footnotetext{
3 Ao utilizarmos como material empírico para este artigo as revistas pedagógicas brasileiras, entendemos que estas representam o pensamento pedagógico de um tempo. Assim, optamos por não destacar os jornalistas/autores das matérias utilizadas, pois o que importa para tal empreitada investigativa é analisar os significados produzidos por estes artefatos culturais como importantes veículos de produção/transmissão de conhecimento pedagógico para os professores brasileiros.
} 
Assim sendo, o texto está organizado em quatro partes. Na primeira apresentamos nossas escolhas teórico-metodológicas com relação ao material empírico, bem como os critérios utilizados para seleção e análise. Na segunda parte exploramos a constituição de uma sociedade de indivíduos (BAUMAN, 2008), considerando-a como contexto para a produção de avaliações cada vez mais personalizadas. A seguir, na terceira parte, realizamos as análises e buscamos mostrar como as revistas pedagógicas têm operado na constituição de processos avaliatórios cada vez mais individualizados e como essa proliferação dos mecanismos de avalição tem atuado em uma maior intensificação e controle do trabalho docente. Na quarta e última parte realizamos uma breve conclusão, apontando quais possibilidades ainda parecem potentes para justificarmos a defesa da escola como espaço de transmissão de uma "cultura comum" (DUSSEL, 2009).

\section{Das Escolhas Teóricas e Metodológicas}

Optamos por utilizar neste artigo a expressão "escolhas teóricas e metodológicas" para marcar que assumimos uma compreensão de que nossas opções metodológicas englobam, para além de um conjunto de procedimentos de como fazer, uma perspectiva teórica. Nas palavras de Meyer e Paraíso (2012, p. 15):

Uma metodologia de pesquisa é sempre pedagógica porque se refere a um como fazer, como fazemos ou como faço minha pesquisa. Trata-se de caminhos a percorrer, de percursos a trilhar, de trajetos a realizar, de formas que sempre têm por base um conteúdo, uma perspectiva ou uma teoria. Pode se referir a formas mais ou menos rígidas de proceder ao realizar uma pesquisa, mas sempre se refere a um como fazer. Uma metodologia de pesquisa é pedagógica, portanto, porque trata de uma condução: como conduzo ou conduzimos nossa pesquisa (grifos das autoras).

Partimos, então, do entendimento, proposto pelas autoras, de que uma metodologia de pesquisa é pedagógica, pois se trata de como conduzimos nossa pesquisa. Nessa seção apresentamos, de forma resumida, como foi realizada a 
seleção e a organização das revistas pedagógicas como material analítico, com o objetivo de justificar o trabalho com esse tipo de artefato para pesquisas em educação.

Antes de apresentar os materiais, acreditamos ser importante marcar que este artigo, ao situar-se em uma perspectiva pós-estruturalista, olha para esses materiais como superfícies analíticas que poderão ajudar a contar sobre as práticas sociais de um determinado tempo. Assim, o que é dito e escrito sobre os processos de avaliação nas revistas pedagógicas será considerado neste artigo como espaço de enunciabilidade e visibilidade (DELEUZE, 2005).

Dentro dessa compreensão, cabe marcar que nossa intenção, neste artigo, não consiste em esgotar analiticamente cada um dos artefatos analisados. Assumimos uma postura investigativa, que busca olhar para o material analítico e suas exterioridades, considerando os diferentes textos como representantes do pensamento pedagógico do nosso tempo. Assim, não os consideramos enquanto emissores privilegiados, mas parte constituinte de condições para as enunciabilidades e visibilidades do que tem se dito sobre os processos de avaliação e como essa constituição de processos avaliativos, cada vez mais individualizados, parece ter uma relação com os processos de individualização que assistimos fortalecer-se contemporaneamente.

A escolha das revistas pedagógicas como material empírico se justifica na esteira de outras pesquisas ${ }^{4}$ desenvolvidas com estes artefatos chamados pedagógicos, que mostram que essas revistas, ao se proporem a discutir questões como a avaliação, foco deste artigo, para além de descrever os significados já existentes para essa temática, têm participado da produção de seus significados na sociedade contemporânea. Já a opção pelas revistas Nova Escola e Pátio deve-se a dois motivos: primeiro, por serem revistas com distribuição gratuita para a rede pública de ensino brasileira, tendo um grande alcance em todo território nacional, constituindo-se materiais de referência para professores, gestores e

\footnotetext{
${ }^{4}$ Aqui destacamos duas pesquisas que tiveram como material empírico as revistas Nova-Escola: Tomio (2013), que investigou o processo de construção do livro didático e Santana (2011), que analisou como a docência era narrada/construída nas publicações analisadas, articulada com a noção de empreendedorismo.
} 
escolas pensarem as temáticas educacionais; segundo, por se encontrar nessas publicações discussões de maior recorrência, relevância e qualidade acerca do tema que aqui discutimos.

Para a análise, utilizaremos especificamente duas edições da revista Nova Escola: a primeira publicada no ano de 2006 com a chamada "Em busca da qualidade na Educação", e a segunda editada no ano de 2012, com o título "Turma heterogênea", tendo como matéria de capa a chamada "Cada um é um! E agora?"; três edições da revista Pátio: a primeira publicada no ano de 2005 : "Aprendizagem para todos", a segunda no ano de 2009: "A escola flexível" e a terceira no ano de 2010: "Educação Customizada". Também integrará o material empírico alguns excertos extraídos dos site da revista Nova Escola que irão auxiliar na argumentação aqui proposta. A escolha desses quatro exemplares ocorreu após uma longa análise das edições publicadas entre os anos de 2005 e 2015. É necessário salientar que, embora outras edições dessas revistas possuam artigos acerca desta temática, as aqui escolhidas têm como chamada central a questão da individualização dos processos formativos e, principalmente, defendem que somente seria possível uma educação customizada por meio de processos avaliatórios mais eficientes. Assim, desejamos mostrar que tais exemplares, ao defenderem que a qualidade na educação passaria por processos de avaliação mais eficientes e individualizados, têm produzido novas configurações no campo pedagógico contemporâneo.

Após justificar a escolha do material e antes de começar a análise dos processos de avaliação no material empírico, realizamos uma breve contextualização dos processos de individualização, que têm se intensificado contemporaneamente, e da responsabilização dos indivíduos como marcas importantes do nosso tempo e que parecem produzir condições de possibilidade para que os processos de avaliação se constituam de forma cada vez mais individualizados e personalizados. Para realizar tal revisão, assumimos como principal fonte as reflexões sociológicas de Zygmunt Bauman (2008), produzidas na obra “A sociedade individualizada: vidas contadas e histórias vividas". 


\section{Contemporaneidade, Individualização e Educação: um diagnóstico}

Sabemos não existir um consenso para designar a sociedade contemporânea. Bauman cunhou a expressão "Modernidade Líquida" (2001) e também utiliza a expressão "Pós-Modernidade" (2010) inspirado em Lyotard; Deleuze (1992) falou em "Sociedade de Controle"; Latour (1994) afirmou que "jamais fomos modernos"; Bell (1977) menciona a "sociedade pós-industrial"; e Lipovetsky e Charles (2004) cunharam a expressão "Hipermodernidade". Cada autor, ao empregar essas expressões, deseja destacar características marcantes do período em que estamos inseridos. Com base nos estudos de Veiga-Neto (2010), Klaus (2011) e Dal'Igna (2011), porém, optamos por utilizar as expressões Modernidade e Contemporaneidade como forma de destacar uma distinção entre duas formas de pensar, duas formas de ser, duas racionalidades distintas.

Cabe explicar que, ao falar sobre Modernidade e Contemporaneidade, percebemos uma mudança de ênfase e não a substituição de uma forma de ser por outra. De acordo com Bauman (2001), a sociedade que entra no século 21 não é menos moderna do que a que entrou no século 20 - poderíamos afirmar que somos modernos de um modo diferente. Para o autor, duas características tornam nova e diferente a nossa situação:

a) A primeira seria o "colapso gradual e o rápido declínio da antiga ilusão moderna: da crença de que há um fim do caminho em que andamos, [...] um Estado de perfeição a ser atingido amanhã, no próximo ano ou no próximo milênio [...]" (2001, p. 37).

b) “A segunda mudança é a desregulamentação e a privatização das tarefas e deveres modernizantes" (2001, p. 37), ou seja, o que costumeiramente era considerada tarefa para a razão humana, foi fragmentada, atribuída agora ao indivíduo e seus recursos.

Ao trazer essas duas características a partir das reflexões realizadas por Norbert Elias, Bauman assevera que, quando Elias substitui o "e" e o "versus" pelo "de" em sua última e póstuma obra "A sociedade dos indivíduos", desloca o modo de compreendermos a sociedade e os indivíduos como duas forças 
opostas para uma forma de compreender como a sociedade hoje é constituída por indivíduos (BAUMAN, 2001). Assim, a Contemporaneidade vai investir de maneira incessante em processos de individualização, e os indivíduos vão passar a operar na produção/reformulação/negociação de uma nova rede de entrelaçamentos que podemos chamar ou não de sociedade.

Nesse processo de individualização, segundo Bauman (2008), a figura dos grandes líderes que poderiam nos dizer o que fazer e aliviar nossa carga de responsabilidade pela consequência de nossos atos, parece não mais existir. No mundo em que vivemos, repleto de indivíduos, temos apenas outros indivíduos que podemos usar como um exemplo a ser seguido, mas a responsabilização é de cada um, inclusive pela escolha de que exemplo seguir.

Essa responsabilização última do indivíduo é uma das formas de organização da sociedade individualizada. Para compreendermos um pouco mais como essa lógica tem se estabelecido, utilizamos a sistematização realizada por Bauman (2008), em que ele analisa algumas características da Modernidade pesada e da Modernidade líquida, contrapondo-as.

A Modernidade pesada tinha um compromisso entre o capital e o trabalho, como uma dependência mútua. A norma dificilmente era colocada em questão, pois era esse compromisso entre o capital e o trabalho que gerava a solução de todas as questões sociais consideradas importantes. Era uma mentalidade de longo prazo. Já na Modernidade líquida a sociedade é liquefeita, fluída, dispersa, espalhada, desregulada. Houve um rompimento entre o capital e o trabalho, tornando a flexibilidade uma necessidade. Assim, podemos observar uma proliferação de contratos precários e cargos sem estabilidade.

Outra característica importante para compreendermos a Contemporaneidade é a mudança na forma de relacionarmo-nos com o espaço. O espaço, na Modernidade, tinha grande importância e, na Contemporaneidade, parece ter cada vez menos. Como exemplo disso, temos a transmissão eletrônica, que, nos dias de hoje, é instantânea. Como resultado desse processo ocorre uma desvalorização do lugar. "O espaço físico, não cibernético, onde as comunicações não-virtuais ocorrem, é apenas um lugar para entrega, absorção e reciclagem do ciberespaço, essencialmente extraterritorial" (BAUMAN, 2008, p. 52-53). 
Seguindo essa lógica, podemos observar o quanto estar no mesmo espaço não significa estar no mesmo lugar físico. Reuniões e conferências, por exemplo, ocorrem cada vez mais dentro deste ciberespaço. Hoje, estamos cada vez mais conectados. O que acontece, por exemplo, no Afeganistão, pode ser acompanhado ao vivo por pessoas de todo o mundo. Querendo ou não, todos nós somos afetados por esses acontecimentos, mas, de forma paradoxal, estamos cada vez mais sós (des-conectados) - sozinhos em uma multidão. Segundo Bauman (2008, p. 69), "a individualização veio para ficar; todos os que pensam sobre os meios de lidar com seu impacto sobre a forma como conduzimos nossas vidas devem começar entendendo esse fato".

O processo de individualização contemporâneo traz também um sentimento de liberdade nunca antes experimentado, o que torna difícil medir as consequências dessa experiência. Um dos grandes perigos destes tempos de incerteza em que vivemos é sermos atingidos pelo que Bauman (2008, p. 70) denominou de "misteriosas forças", que hoje recebem o nome de queda de demanda de trabalho, recessão, racionalização, redimensionamento, entre tantos outros exemplos que vêm à mente neste momento. Vivemos assombrados por esses fantasmas da Contemporaneidade. A mensagem passada para todos parece simples: todos nos tornamos redundantes, substituíveis, ou seja, vulneráveis. Nas palavras do autor (2008, p. 72):

As sociedades que um dia lutaram para que seu mundo se tornasse transparente, à prova de perigos e livre de surpresas, agora encontram suas capacidades de atuação atadas aos anônimos mutáveis e imprevisíveis de forças misteriosas, como as finanças mundiais e as bolsas de valores, ou observam de maneira impotente, sem serem capazes de fazer muito, o contínuo encolhimento do mercado de trabalho, a crescente pobreza, a irrefreável erosão da terra arável, o desaparecimento das florestas, os crescentes volumes de dióxido de carbono no ar e o aquecimento do planeta. As coisas - sobretudo as mais importantes de todas - estão "escapando ao nosso controle".

Cada vez mais criamos e somos apresentados a fórmulas para lidar com os problemas que estão prestes a acontecer, mas igualmente crescem os novos riscos e perigos que surgem a cada novo movimento que fazemos. A solução 
recorrente a ser apresentada para combatermos alguns dos efeitos colaterais da competitividade desregulamentada, por mais controverso que possa parecer, seria mais desregulamentação, maior flexibilização e menos interferência.

Ganhamos liberdade, porém, perdemos segurança. Como mostra Bauman (2008), ao lutarem por mais liberdade nossos ancestrais não poderiam prever que o preço que pagaríamos por essa liberdade seria a insegurança. Não sabemos mais em quem confiar, pois ninguém pode dar uma garantia confiável de que as coisas irão pela direção planejada. Assim, passar por processos de individualização, na Contemporaneidade, não parece ser uma escolha: “[...] a individualização é um destino, não uma escolha: na terra da liberdade individual de escolha, a opção de escapar à individualização e de se negar a participar no jogo individualizante não faz parte, de maneira alguma, da agenda" (BAUMAN, 2008, p. 64). Desse modo, se ficamos doentes, é porque não seguimos uma dieta, não fazemos atividades físicas ou não visitamos nosso médico regularmente; se ficamos desempregados, é porque não desempenhamos nossa atividade com afinco, não buscamos formação e aperfeiçoamento suficiente, não cultivamos boas relações interpessoais. Esses são apenas alguns exemplos de uma responsabilização extrema dos indivíduos que percebemos contemporaneamente.

Essas reflexões realizadas por Bauman (2001) sobre o crescente sentimento de insegurança ao refletir sobre a Modernidade Líquida, são retomadas e ampliadas alguns anos depois para apresentar A Sociedade Individualizada (BAUMAN, 2008). Nesta obra, o autor aponta algumas características da Contemporaneidade que vêm contribuindo para o aumento de nossa insegurança, resumidas assim:

a)falta de ordem e estrutura. Depois de vivermos muitos anos com divisões nítidas e objetivos claros, hoje vivemos em um mundo desprovido de uma estrutura visível, ou de alguma lógica;

b)a desregulamentação universal. O Estado tem abandonado seus deveres tradicionais, deixando a promoção de mercado como uma garantia de uma chance universal para o autoenriquecimento; 
c) outras redes de segurança. $\mathrm{O}$ apoio que nos era oferecido por familiares e pela vizinhança, em que tínhamos a oportunidade de curar as feridas causadas pelo mercado, tem se mostrado cada vez menor e mais fraco;

d)instabilidade dos acontecimentos. Tudo pode acontecer, mas nada irá durar para sempre. Isso pode estar gerando o que Bauman (2008, p. 115) denominou de "identidade palimpséstica", uma identidade que tem facilidade para se adaptar a este mundo em que a capacidade de esquecer tem se tornado mais importante do que a arte de memorizar, demandando que nos adequemos continuamente a novas situações.

Essas são algumas dimensões que Bauman (2008) destaca para explicar o sentimento de incerteza pós-moderna, os processos de individualização vivenciados de forma cada vez mais intensa e a responsabilização dos indivíduos. Queremos mostrar que tais dimensões parecem operar na produção de outros significados para diversos elementos educacionais. Entre eles destacamos: currículo, formação de professores, estratégias de ensino e aprendizagem e também os processos de avaliação. $\mathrm{O}$ acompanhamento constante do aluno e a construção de procedimentos de avaliação cada vez mais individualizados e personalizados, parece encontrar condições de emergência no contexto descrito nessa seção. A seguir passamos para a análise do material empírico, propriamente dito, e buscamos dar visibilidade para como a proliferação dos processos de avaliação tem atuado na intensificação e no controle do trabalho docente, fortalecendo a necessidade de que a educação se constitua de forma cada vez mais individualizada.

Observação atenta, registros diários e a construção de portfólios: a proliferação dos processos de avaliação, a intensificação do trabalho docente e o fortalecimento de uma educação customizada

No ano de 1996 temos a publicação da nova Lei de Diretrizes e Bases da Educação Nacional. Segundo tal documento, uma nova concepção de avaliação deveria permear o processo pedagógico. Em seu artigo $24^{\circ}$ a lei preverá que a verificação do rendimento dos estudantes observará alguns critérios específicos, como avaliação como um processo contínuo e cumulativo, prevalência dos as- 
pectos qualitativos sobre os quantitativos e dos resultados ao longo do período sobre eventuais provas finais. Ressaltamos que com esse artigo não desejamos nos posicionar contra a avaliação processual, mas mostrar como o deslocamento para essa nova concepção de avaliação foi traduzido pelo pensamento pedagógico contemporâneo por intermédio das revistas pedagógicas e tem produzido intensificação e maior controle do trabalho docente e o fortalecimento de uma educação cada vez mais customizada. Em outras palavras, não negamos neste escrito a necessidade de que os processos de avaliação necessitem considerar a singularidade, a diferença e a trajetória escolar dos alunos; mas evidenciar que as revistas analisadas, ao defenderem a constituição de processos avaliatórios cada vez mais individualizados, têm colocado em xeque o objetivo maior da escola, que seria a transmissão de uma cultura comum e universal.

Iniciamos nossas análises apresentando dois excertos da revista Pátio, em que uma escola flexível e uma educação customizada são defendidos como princípios que devem orientar uma nova prática pedagógica que considere os interesses e as necessidades dos alunos como elementos norteadores para a prática pedagógica do professor:

As práticas de ensino tornam-se flexíveis quando consideram essa emancipação, que é própria de todos os alunos, independentemente da capacidade de aprender de cada um, e os reconduzem ao lugar de saber do qual foram excluídos, tanto na escola quanto fora dela. Na mesma direção, as atividades escolares diversificam-se para que todos os alunos possam escolhê-las livremente, em vez de serem predestinadas e direcionadas para um grupo ou outro da turma. É preciso coragem e humildade para rever a organização pedagógica das escolas, à luz de concepções de ensino e de aprendizagem inovadoras, e para abandonar os arranjos criados para manter as aparências de práticas que são "bem-intencionadas", mas que acabam por atribuir apenas ao aluno a responsabilidade por seu fracasso e por sua incapacidade de acompanhá-las em todos os níveis de ensino.

Fonte: PÁTIO, 2008-2009, p. 18 (grifos nossos). 
Está na hora de reencontrarmos as necessidades individuais dos alunos e de repensarmos o nosso papel na sua formação, não só dos ditos “diferentes", mas de todos aqueles com os quais temos um compromisso educacional. À pergunta inicialmente colocada a respeito de como atender os alunos em sua individualidade, respondo: considerando a diversidade e a heterogeneidade como elementos essenciais da dimensão criativa dos seres humanos, bem como reconstruindo a escola que valoriza essa dimensão. Se a escola "homogênea" foi construída historicamente, a escola da heterogeneidade e da diversidade também o será. E então poderemos falar em uma escola para todos.

Fonte: PÁTIO, 2010, p. 20 (grifos nossos).

Em ambos os excertos podemos verificar a necessidade de o professor considerar em sua proposta pedagógica os alunos em sua individualidade e oferecer atividades diversificadas e escolhas curriculares para que eles possam optar, a partir desse "cardápio" oferecido pelo professor, qual atividade lhe seria mais interessante. Desejamos destacar com esses excertos o quanto nos parece que pautar uma proposta pedagógica a partir dos interesses dos estudantes é uma forma de transmitir para o aluno a responsabilidade por seu processo formativo. Como buscamos mostrar na seção anterior, essa responsabilização dos indivíduos é uma das características fundantes do processo de individualização que vivenciamos contemporaneamente. ${ }^{5}$

\footnotetext{
5 Entendemos que a individualização é um processo importante para a constituição e o fortalecimento de uma sociedade democrática, pensamento que se ampara no liberalismo. Na educação, podemos evidenciar tal pensamento na publicação do Manifesto dos Pioneiros da Educação Nova (1932) que já defendia que a educação deveria "servir não aos interesses de classe, mas aos interesses dos indivíduos, e que se funda sobre o princípio da vinculação da escola como meio social, tem seu ideal condicionado pela vida social atual, mas profundamente humano de solidariedade, de serviço social e cooperação (AZEVEDO et al. 1932, p. 40-41). Os processos de individualização, porém, que aqui analisamos, ao responsabilizar os indivíduos tem como base o pensamento neoliberal e, portanto, configuram um declínio do papel do Estado.
} 
Para que essa educação personalizada possa se constituir, será necessário que uma nova forma de docência também seja constituída. Assim, as revistas pedagógicas aqui analisadas irão defender a constituição de uma docência flexível, em que o professor se constitua como um facilitador das aprendizagens dos alunos, como podemos observar no excerto a seguir:

O professor é facilitador da aprendizagem, e não fonte de conhecimento. Os professores são organizadores do ambiente em sala de aula, das experiências de aprendizagem, dos recursos e das condições procedimentais e práticas de aprendizagem.

Fonte: PÁTIO, 2004-2005, p. 16.

Assim, o professor flexível, como analisam Masschelein e Simons (2014, p. 146), "não é mais alguém que é arrebatado por seu assunto e vive para ele, mas alguém que pode ser arrebatado por tudo - na medida em que a demanda exija". Essa necessidade de que o professor constitua o seu trabalho de acordo com as carências e os interesses dos alunos, é mostrada pelos autores como uma necessidade de organizar o trabalho docente a partir de uma demanda de mercado, transformando os processos educacionais em processos cada vez mais empresariais e comerciais. Ao compreendermos que a lógica do mercado passa a operacionalizar o trabalho pedagógico, observamos igualmente uma precisão de maior controle dessa atividade. Assim, desejamos mostrar que a proliferação dos mecanismos de avaliação aja em dois polos do sistema educacional - se com relação ao trabalho docente tais mecanismos atuam produzindo maior intensificação e controle, com relação aos estudantes produz uma responsabilização destes por seu processo formativo e uma educação cada vez mais individualizada e personalizada - uma educação customizada.

As revistas analisadas, ao discorrerem sobre uma nova concepção de avaliação, vão defender a utilização de diferentes recursos que auxiliem o professor a acompanhar o desenvolvimento de seus alunos de forma individualizada. Um dos instrumentos que encontramos bastante recorrência seria o portfólio, como podemos observar nos excertos a seguir: 
PORTFÓLIO EXIBE OS AVANÇOS: fazer um portfólio com as produções da garotada durante sua permanência na escola é fundamental para ajudar a acompanhar o progresso de cada um e planejar novas intervenções.

Fonte: NOVA ESCOLA, 2006, p. 45.

PORTFÓLIO: Instrumento de avaliação proporciona visão geral e ao mesmo tempo detalhada sobre o processo de aprendizagem do aluno.

Na educação, o portfólio tomou uma função ainda maior, e se tornou um instrumento de avaliação, que dá visibilidade ao conhecimento apreendido, que leva à reflexão, que evidencia os diferentes elementos do desenvolvimento do aluno.

Fonte: NOVA ESCOLA, 2016.

O objetivo de organizar o portfólio, como podemos observar nos excertos anteriormente destacados, seria auxiliar o professor no acompanhamento de cada aluno de forma individual e também fornecer elementos para que o docente possa planejar as próximas intervenções pedagógicas para esse aluno. Para marcar a importância desse instrumento, a revista de 2006 apresenta o exemplo de um menino, Diogo, ressaltando que foi mediante este instrumento que se pôde observar seu crescimento. Já a matéria de 2016 apresenta o exemplo da professora Mara. Ela, a partir de sua experiência, aponta a importância da utilização do portfólio como estratégia de acompanhamento e avalição individual dos alunos. A matéria ressalta que a produção de portfólios historicamente tem sido associada a uma coletânea organizada de trabalhos executados em um determinado período de tempo por diferentes profissionais, como fotógrafos, desenhistas e arquitetos. Assim, esse documento era uma forma de expor suas qualidades e experiências profissionais. No campo pedagógico, todavia, esse documento teria um valor ainda maior, por esse material poder constituir-se como uma ferramenta de avalição. Ao trazermos uma matéria publicada no ano de 2006 e outra no ano de 2016 sobre a importância de utilização de portfólios no campo educacional, desejamos mostrar o quanto esse tipo de procedimento avaliatório cada vez mais tem se consolidado como uma ferramenta importante para o campo pedagógico. 
A partir da análise do material empírico fica evidente que outros mecanismos de avaliação poderão/deverão ser empregados pelos docentes como forma de acompanhar os estudantes: observação atenta, registros diários e a construção de portfólios individualizados parecem ser a chave apresentada pelas revistas para a elaboração de um processo pedagógico de mais qualidade, como podemos observar no excerto a seguir:

Nesse sentido, vale lembrar que todas as atividades oferecem elementos para avaliação. A observação de todos no dia a dia é sempre de grande valia para o professor. Para acompanhar a aprendizagem das crianças é preciso fazer registros diários sobre o desempenho delas e compilar os trabalhos que realizam em sala. Esse material pode ser transformado num portfólio (arquivo da produção dos alunos). A periodicidade com que esses registros são transformados em notas depende da política educacional de cada escola. Pode ser bimestral ou trimestral.

Fonte: NOVA ESCOLA, 2009 (grifos nossos).

O que desejamos refletir, com base nos excertos anteriormente destacados, é que essa transformação na concepção dos processos e dos instrumentos de avaliação tem operado em uma maior intensificação e controle do trabalho docente. O processo de intensificação do trabalho docente, segundo Apple (1995, p. 39), é: "uma das formas tangíveis pelas quais os privilégios dos/as trabalhadores/as educacionais são degradados". Isto posto, entendemos que a criação da necessidade de se ampliar as ferramentas de avaliação por meio da confecção de tabelas para o acompanhamento individual do aluno, cadernos de observação com registros diários e organização de portfólios individuais que apresentem o desenvolvimento de cada aluno, tem produzido uma intensificação do trabalho docente.

Gandin e Lima (2015, p. 671), ao analisarem as transformações no trabalho das professoras a partir da introdução de um programa de intervenção pedagógica, vão mostrar que a intensificação do trabalho docente ocorre "na medida em que as professoras passam a exercer outras atividades que não apenas em termos pedagógicos, mas também de gestão da sala de aula." Com isso os professores precisariam aprender novas habilidades às quais não estão 
habituados para dar conta da nova demanda criada pelo programa analisado. Acreditamos que a proliferação de mecanismos de avaliação cria a necessidade de os professores constituírem habilidades que são mais ligadas à gestão da sala de aula do que dos processos pedagógicos que permeiam a relação professor-aluno, produzindo maior intensificação e controle do trabalho docente. Essa intensificação do trabalho docente parece derivar do novo lugar que a avaliação tem ocupado no discurso pedagógico contemporâneo. Assim, ao centralizar o controle do trabalho docente pelas avaliações cada vez mais individualizadas, visualizamos uma centralidade em habilidades de gestão de sala de aula em detrimento dos saberes docentes.

Outro aspecto que queremos destacar é a significação atribuída aos conhecimentos no processo de avaliação no material analisado:

A avaliação deve ser planejada para que mostre qualquer progresso obtido pela criança, mesmo que este seja muito lento. Pequenas etapas de avaliação demonstram tal progresso, o que passa a ser bastante motivador para o aluno - assim como para o professor.

Fonte: PÁTIO, 2008-2009, p. 13.

Na sequência, propus que cada jovem escolhesse um material para explorar mais uma vez - como o que mais gostou ou o mais desafiador. Meu objetivo era deixar todos irem mais a fundo na experiência. Para encerrar, as produções foram organizadas em portfólios individuais e a turma pôde ver as criações e discutir. E, assim, eu vi com clareza o percurso de cada um e avaliei a aprendizagem do grupo.

Fonte: NOVA ESCOLA, 2012, p. 47.

Dentro dessa nova concepção de avaliação, apresentada por meio de exemplos nos excetos aqui destacados, será necessário que o professor construa um documento com o objetivo de mostrar qualquer progresso obtido pela criança, ou, ainda, que estimule os jovens a optarem por explorar de forma mais aprofundada as atividades que lhe produzirem maior interesse. Parece-nos que a adoção dessas novas estratégias de avaliação, ao invés de produzir uma maior interação com os conhecimentos escolares, têm operado no esmaecimento da necessidade de transmissão cultural. Essa proliferação de mecanismos de 
avaliação ou controle que vivenciamos contemporaneamente, foi denominada pelo pesquisador Alfredo Veiga-Neto (2013) de "delírios avaliatórios", e tem produzido, além de uma intensificação do trabalho docente, uma nova relação dos professores e dos alunos com os conhecimentos escolares.

Veiga-Neto (2013), ao analisar essa intensificação dos processos de avaliação, mostra que parece ter se constituído no campo pedagógico uma verdade educacional, na qual, se aperfeiçoássemos nosso sistema de avaliação, de forma imediata melhoraríamos também nosso sistema educacional. Nas palavras do autor: "Por toda parte, parece que, por si só e num passe de mágica, do aperfeiçoamento da avaliação resultará o aperfeiçoamento da educação [...]. O salvacionismo pedagógico parece estar apostando, hoje e cada vez mais, todas as fichas na capacidade de avaliação" (VEIGA-NETO, 2013, p. 9). Desse modo, entendemos que as revistas pedagógicas, ao defenderem uma avaliação que mostre e valorize qualquer progresso obtido pela criança e que dê visibilidade a esses progressos por meio de portfólios individuais, têm fortalecido esse salvacionismo pedagógico que articula melhoria da qualidade na educação a processos de avaliação mais eficientes.

Articular a ideia de melhoria da qualidade da educação a processos avaliativos parece ser uma forma sutil e produtiva de convencer todos os envolvidos no processo de que esses procedimentos avaliativos são fundamentais. Estamos avaliando mais, e isto é fato. A questão que se coloca é: Estamos ensinando mais? Nossos alunos têm aprendido mais? Entendemos ser importante realizar um breve recuo histórico para mostrar que a relação qualidade na educação e procedimentos avaliatórios mais eficientes é uma construção histórica datada e que pode ser problematizada. Tendo isso em vista, apresentamos uma sucinta reflexão sobre essa construção, tomando como referência os estudos do pesquisador Díaz Barriga (2001), para, após, seguir as análises do material empírico.

Segundo o pesquisador, podemos visualizar que essa relação de imanência que se estabeleceu entre exame e ação educativa é uma construção histórica a partir de três motivos: (1) o exame foi um instrumento criado pela burocracia chinesa para eleger membros de castas inferiores; (2) existem várias evidências de que, na Idade Média, não existiam exames ligados à prática educativa; (3) a 
atribuição de notas a trabalhos escolares é uma herança do século 19. A partir destes tópicos, apontados por Díaz Barriga (2001), podemos inferir que o exame não é um problema que se volta historicamente ao conhecimento, mas tem seu foco voltado para questões sociais, muitas delas sem solução. Nas palavras do pesquisador:

Assim, o exame é na realidade um espaço de convergência de inúmeros problemas. Problemas que são das mais diversas ordens. Podem ser sociológicos, políticos e também psicopedagógicos e técnicos. No entanto, por um reducionismo que no fundo cumpre a função de ocultar a realidade, os problemas em relação ao exame aparecem agudizados só em sua dimensão técnica. Desconhecendo os outros âmbitos de estruturação (DÍAZ BARRIGA, 2001, p. 56).

Podemos observar que, historicamente, uma amplitude de problemas é sintetizada pelo exame, depositando-se várias expectativas na ação de examinar. A solução para diversos problemas que a sociedade não tem conseguido "dar conta", como a questão da não aprendizagem dos alunos, poderia ser solucionada com a utilização de um sistema de avaliação eficaz. De acordo com Díaz Barriga (2001, p. 57), porém, “[...] o exame é só um instrumento que não pode por si mesmo resolver os problemas gerados por outras instâncias sociais".

Após essa breve explanação de como se construiu historicamente a relação qualidade e avaliação e de que a relação entre a construção de conhecimentos e a avaliação não é uma relação imanente, consideramos importante seguir essa reflexão analisando como essa proliferação de mecanismos de avaliação parece estar fortalecendo a constituição de uma educação cada vez mais customizada e que essa constituição não parece estar atuando no aumento dos processos de ensino e de aprendizagem na relação pedagógica.

Fabris e Traversini (2013), ao analisarem pareceres descritivos de professores sobre alunos dos últimos anos do Ensino Fundamental, encontraram resultados semelhantes aos defendidos neste artigo. As autoras mostram que somente $20 \%$ dos pareceres explicitavam conhecimentos aprendidos nas 
disciplinas. Elas evidenciam também uma centralidade de investimentos em duas etapas do currículo escolar: metodologias e avaliação, e uma ênfase nos comportamentos e enfraquecimento do conhecimento das áreas específicas.

Nos materiais analisados também é possível observar uma ênfase na participação dos alunos em algumas atividades, especialmente com foco na socialização e no comportamento; assim, o professor é aconselhado a avaliar cada avanço, cada progresso, como podemos perceber nos excertos apresentados anteriormente.

O registro diário e a ideia de que todas as atividades oferecem elementos para a avaliação parecem ser essenciais na Contemporaneidade e têm uma relação com os elementos apontados anteriormente relacionados a uma sociedade de indivíduos. A avaliação deve considerar todas as atividades realizadas por aluno e, como já foi apontado anteriormente, deve evidenciar qualquer progresso que este obteve. A avaliação focada nesses aspectos nos permite continuar refletindo sobre a função da escola contemporânea, pois ela parece constituir-se muito mais como um centro de convivência (FABRIS, 2014) do que como um espaço onde se produz conhecimento. Será que ainda existe espaço para ensinar e aprender na escola de hoje?

As análises realizadas por Fabris (2014) em uma pesquisa sobre os significados atribuídos à escola por alunos e professores, mostram que a ênfase pedagógica se encontra na convivência e não em conhecimentos, reforçando o argumento que desejamos desenvolver. A autora também evidencia que os alunos ainda veem a escola como o espaço que pode ajudá-los a melhorar de vida, a realizar seus sonhos; portanto, os conhecimentos a serem aprendidos na escola são entendidos por crianças/jovens como passaporte para a realização desses sonhos. Esse pode ser um caminho para produzir alguns movimentos com relação às aprendizagens. Segundo Fabris (2014, p. 65), "a escola ainda é a instituição que tem compromisso em fazer chegar a todas as classes sociais o conhecimento culturalmente legitimado. Como as escolas têm assumido esse compromisso?" 
Para concluir essa seção, gostaríamos de retomar a pesquisa sobre os processos avaliativos de Fabris e Traversini (2013). Conforme as autoras, se, por um lado, podemos compreender a flexibilidade como uma possibilidade para entender o tempo atual vivido pelos alunos, por outro essa flexibilidade pode ser um indício dos mecanismos de controle instaurando-se nas salas de aula.

Juntamente com as autoras, apontamos a importância do conhecimento na escola pública contemporânea. Acreditamos e defendemos que a centralidade em processos de avaliação cada vez mais individualizados e a defesa por uma educação customizada têm produzido um esmaecimento da escola como espaço para transmissão de uma "cultura comum" (DUSSEL, 2009) e nos perguntamos o quanto essa configuração pode ser prejudicial, especialmente para uma camada da população brasileira. Parece-nos que o fortalecimento desses mecanismos tem contribuído para a constituição de uma "escola em duas velocidades" (NÓVOA, 2009): uma escola que tem como centralidade o acolhimento social, com foco nos processos de avaliação, que devem considerar qualquer progresso obtido pelo aluno, voltada para os pobres; e uma escola fortemente ancorada nos processos de ensino e de aprendizagem para os filhos dos ricos.

A partir do material empírico e das análises apresentadas nessa seção, desejamos marcar nossa associação às pesquisadoras e pesquisadores que têm defendido a escola como local onde o conhecimento é ensinado e construído. Acreditamos que a escola ainda é um dos locais em que as crianças, os jovens e suas famílias podem depositar a esperança para a construção de uma vida mais justa e mais feliz; para isso, precisamos assumir o compromisso com o conhecimento e olhar com suspeita, investigando os efeitos da centralidade nos processos de avaliação e os investimentos realizados na produção de uma educação cada vez mais customizada. Encaminhamo-nos para a última seção, fazendo uma reflexão dos desdobramentos dos mecanismos analisados e perguntando-nos se estaríamos nos dirigimos para o fim da escola como espaço de transmissão de uma "cultura comum” (DUSSEL, 2009). 


\section{Fim da Escola como Espaço para Transmissão de uma "Cultura Comum"?}

O desafio é estruturar uma ideia de cultura comum que possa ser transmitida e compartilhada, que leve em conta as injustiças e privilégios do passado e que ao mesmo tempo proponha algumas outras inclusões que não venham da mão da cultura do mercado ou do indivíduo do autodesenho (DUSSEL, 2009, p. 359).

Terminamos este artigo buscando tecer uma reflexão sobre a pergunta que é trazida como título de tal empreitada. Estaríamos presenciando o fim da escola como espaço para transmissão de uma "cultura comum"? Para realizar tal reflexão, como apresentamos na introdução deste texto, iremos retomar as contribuições do pensamento de Inés Dussel (2009), quando, em um texto sobre a crise da transmissão escolar, a pesquisadora, ao investigar os modos pelos quais o ideal de transmitir uma cultura comum a todos na escola tem sido posicionado no nosso tempo, mostra que os constantes ataques realizados sobre a transmissão cultural parecem ter como justificativas centrais duas questões: 1 - o declínio das humanidades; e 2 - a crise da ideia de reprodução cultural.

O primeiro elemento apresentado pela autora teria uma relação com o declínio da concepção da escola como via para a realização pessoal e para a ascensão social. Assim, o ideal de cultura comum esteve, em sua origem, ligado a um núcleo de humanidades modernas que estabelecia o que deveria ser passado às novas gerações. Eram as humanidades que ofereciam “[...] um núcleo de referências comuns que permitiam às pessoas sentir-se parte de alguma coisa comum, de uma vida comunitária - com suas hierarquias, inclusões e exclusões... mas comum enfim" (DUSSEL, 2009, p. 352).

O segundo elemento que tem colocado a transmissão cultural em questão seria uma crise geral da noção de transmissão e de reprodução cultural. A pesquisadora mostra que, considerando o contexto atual de liquidez e de perspectivas cada vez mais instáveis, a necessidade de transmissão e reprodução cultural torna-se um alvo fácil. Dessa forma, as ideias pedagógicas contemporâneas que festejam a autonomia, a criatividade e a independência, podem estar produzindo 
sujeitos que se tornam escravos desse processo, lançando-se sobre "[...] cada um de nossos ombros a tarefa e a responsabilidade de construir nosso sucesso ou, o que é mais provável, de suportar e explicar nosso fracasso (DUSSEL, 2009, p. 358).

No cenário brasileiro também evidenciamos estudos que apresentam uma preocupação com o declínio da transmissão cultural, especialmente nas discussões relativas aos estudos curriculares. Apontamos as contribuições do estudo realizado por Silva (2016), que, ao realizar uma problematização acerca das temáticas de currículo, conhecimento e transmissão cultural, apresenta um diagnóstico do pensamento social do século 20, que nos ajuda a compreender como a questão da transmissão escolar tem sido abordada no pensamento pedagógico contemporâneo. O pesquisador, ao examinar as obras de Émile Durkhein, Antonio Gramsci e Hannah Arendt, nos convida a um reencontro com autores significativos para a contemporaneidade pedagógica e que parecem ter sido esquecidos nas últimas décadas. $\mathrm{O}$ autor destaca, em suas conclusões, que, ao revisitar tais pensadores, ele não evidencia “[...] definições estáticas para a função da transmissão cultural, nem mesmo cristalizações para o delineamento dos conhecimentos a serem ensinados" (SILVA, 2016, p. 180). Assim, o texto apresenta como desafio para o pensamento pedagógico contemporâneo a necessidade de potencializarmos a escolarização e as diferentes formas de transmissão cultural como uma tarefa do nosso tempo.

Considerando o diagnóstico mais amplo apresentado nesse texto, em que vivenciamos de forma cada vez mais intensa o individualismo e a responsabilização dos indivíduos, e, observando que dentro do recorte educacional defende-se o estabelecimento de uma educação customizada e de processos formativos e avaliativos cada vez mais personalizados, nos perguntamos se ainda seria possível estabelecer alguns elementos que possam agir como referência para todos.

Para enfrentarmos esse desafio que se impõe, Dussel (2009) apresenta quatro critérios gerais que podem nos auxiliar a repensar a transmissão cultural a partir da escola. O primeiro critério consiste em compreendermos que a nossa constituição como sujeitos prescinde de um confronto com a alteridade. Assim, 
a escola "[...] deveria poder nos ajudar a nos relacionar mais livremente com uma tradição, e, por isso mesmo, também deveria dar a essa tradição um lugar para que seja reescrita" (DUSSEL, 2009, p. 360).

O segundo critério seria a necessidade de a escola oferecer resistência à aceleração dos tempos, da pressão da performance e da necessidade contemporânea de nos reinventarmos o tempo todo. Aqui, caberia às instituições escolares "[...] oferecer um contexto em que se possa repousar "no outro", numa herança acumulada, num saber que o outro nos oferece, num espaço onde se possa errar e voltar a provar sem maiores consequências".

O terceiro critério traduz-se na necessidade de a escola oferecer chaves para que os alunos possam decifrar a experiência comum. Nessa tarefa seria importante:

[...] recorrer às disciplinas para que nos forneçam modos de abordagem, linguagem, regras, que nos ajudem a construir alguma ordem e algum sentido ou interpretação que construam uma distância, [...], para que o indivíduo possa ser também indivíduo estranhando-se, sendo capaz de apor uma distância justa entre o vivido e a construção de uma experiência (DUSSEL, 2009, p. 360).

O quarto critério apresentado pela pesquisadora seria a busca por encontrar um modo de transmissão cultural que não tenha como ponto de partida um gesto amargo e desencantado. Assim sendo, as escolas, as instituições depositárias do passado e responsáveis pelo futuro dos jovens, ao compreenderem que não são mais o centro das referências culturais, precisam evitar a nostalgia e a amargura.

Ao nos propormos, nesse breve exercício analítico, a examinar e problematizar os significados acerca dos processos de avaliação escolar que, contemporaneamente, são produzidos no interior do discurso pedagógico e os modos pelos quais são visibilizados por revistas brasileiras, buscamos mostrar como esses processos têm contribuído para uma educação cada vez mais individual e customizada. Nossas análises seguiram dois caminhos distintos, porém conectados: em um primeiro momento realizamos um diagnóstico para mostrar que a produção de avaliações cada vez mais individualizadas, expressas em 
nosso material empírico por meio de excertos, como a construção de portfólios individuais encontra-se ligada à necessidade de acompanhar o progresso de cada um, parece ter como condição de possibilidade para emergir e se fortalecer uma sociedade individualizada, onde os indivíduos são responsabilizados unilateralmente por seus sucessos e fracassos (BAUMAN, 2008); e no segundo momento mostramos que a proliferação de mecanismos de avaliação tem atuado na intensificação e no maior controle do trabalho docente.

Para concluir, retomamos a epígrafe que utilizamos para abrir essa conclusão, na qual o desafio que parece se impor é a necessidade de construirmos uma ideia de cultura comum que, ao mesmo tempo que forneça chaves para os jovens compreenderem o nosso tempo, possa fomentar a construção de novas subjetividades que não venham na "mão da cultura do mercado ou do indivíduo do autodesenho" (DUSSEL, 2009, p. 359).

\section{Referências}

APPLE, Michael. Trabalho docente e textos: economia política e relações de classe e gênero na educação. Porto Alegre: Artes Médicas, 1995.

AZEVEDO, Fernando et al. O manifesto dos pioneiros da educação nova. São Paulo: Nacional, 1932.

BAUMAN, Zygmunt. Modernidade líquida. Tradução José Gradel. Rio de Janeiro: Jorge Zahar, 2001.

. A sociedade individualizada: vidas contadas e histórias vividas. Tradução Plínio Dentzien. Rio de Janeiro: Jorge Zahar, 2008.

. Legisladores e intérpretes: sobre modernidade, pós-modernidade e intelectuais. Rio de Janeiro: Jorge Zahar, 2010.

BELL, Daniel. O advento da sociedade pós-industrial: uma tentativa de previsão social. São Paulo: Cultrix, 1977.

DAL'IGNA, Maria Cláudia. "Família S/A": um estudo sobre a parceria família-escola. 2011. Tese (Doutorado em Educação) - Universidade Federal do Rio Grande do Sul (UFRGS), Programa de Pós-Graduação em Educação, Faculdade de Educação, Porto Alegre, 2011. 
DELEUZE, Gilles. Controle e devir. In: DELEUZE, Gilles. Conversações. São Paulo: Editora 34, 1992. p. 209-218.

Foucault. Lisboa: Edições 70, 2005.

DÍAZ BARRIGA, Angel. Uma polêmica em relação ao exame. In: ESTEBAN, Maria Teresa (Org.). Avaliação: uma prática em busca de novos sentidos. Rio de Janeiro: DP\&A, 2001. p. 51-92.

DUSSEL, Inés. A transmissão cultural assediada: metamorfoses da cultura comum na escola. Cadernos de Pesquisa, v. 39, n. 137, p. 351-365, 2009.

FABRIS, Elí Terezinha Henn; TRAVERSINI, Clarice Salete. Conhecimentos escolares sob outras configurações: efeitos das movimentações disciplinares e de controle? In: TRAVERSINI, Clarisse Salete et al. (Org.). Currículo e inclusão na escola de Ensino Fundamental. Porto Alegre: EDIPUCRS, 2013.

FABRIS, Elí Terezinha Henn. A escola contemporânea: um espaço de convivência? In: SILVA, Roberto Rafael Dias da (Org.). Currículo e docência nas políticas de ampliação da jornada escolar. Porto Alegre: Evangraf, 2014, p. 47-66.

GANDIN, Luís Armando; LIMA, Iana Gomes de. Reconfiguração do trabalho docente: um exame a partir da introdução de programas de intervenção pedagógica. Revista Brasileira de Educação, Rio de Janeiro, v. 20, n. 62, p. 663-677, set. 2015.

KLAUS, Viviane. Desenvolvimento e governamentalidade (neo)liberal: da administração à gestão educacional. 2011. Tese (Doutorado em Educação) - Universidade Federal do Rio Grande do Sul, 2011.

LATOUR, Bruno. Jamais fomos modernos - ensaio de antropologia simétrica. Rio de Janeiro: Editora 34, 1994.

LIPOVETSKY, Gilles; CHARLES, Sébastien. Os tempos hipermodernos. São Paulo: Barcarolla, 2004.

MASSCHELEIN, Jan; SIMONS, Maarten. Em defesa da escola. Belo Horizonte: Autêntica, 2014.

MEYER, Dagmar Estermann; PARAÍSO, Marlucy Alves. Metodologias de pesquisas pós-críticas ou sobre como fazemos nossas investigações. In: (Org.). Metodologias de pesquisas pós-críticas em educação. 2. ed. Belo Horizonte: Mazza, 2012. p. 15-22. NOVA ESCOLA. A revista de quem educa. Em busca da qualidade na educação. São Paulo: Fundação Victor Civita, n. 196, out. 2006.

A revista de quem educa. Saberes e atitudes de alunos com deficiência. São Paulo: Fundação Victor Civita, jul. 2009. Disponível em: <https://novaescola.org.br/ conteudo/1901/saberes-e-atitudes-de-alunos-com-deficiencia>. Acesso em: 15 ago. 2017. 
NOVA ESCOLA. A revista de quem educa. Turma heterogênea. São Paulo: Fundação Victor Civita, n. 255, set. 2012.

NÓVOA, António. Professores: imagens do futuro presente. Lisboa: Educa, 2009.

PÁTIO. Revista pedagógica. Aprendizagem para todos. Porto Alegre: Artmed, n. 32, nov. 2004/jan. 2005. jan. 2009.

Revista pedagógica. A escola flexível. Porto Alegre: Artmed, n. 48, nov. 2008/

. Revista pedagógica. Educação customizada. Porto Alegre: Artmed, n. 55, out. 2010.

SANTANA, Dalva. Entrelaçamentos entre docência e empreendedorismo na Revista Nova Escola. Dissertação (Mestrado em Educação) - Programa de Pós-Graduação em Educação, Universidade Luterana do Brasil (Ulbra), Canoas, 2011.

SCHERER, Renata Porcher. "Cada um aprende de um jeito": das adaptações às flexibilizações curriculares. 2014. 170f. Dissertação (Mestrado em Educação) - Universidade do Vale do Rio dos Sinos, Programa de Pós-Graduação em Educação, São Leopoldo, 2014.

SILVA, Roberto Rafael Dias da. Políticas de constituição do conhecimento escolar para o Ensino Médio no Rio Grande do Sul: uma analítica de currículo. Educação em Revista, Belo Horizonte, v. 30, n. 1, p. 127-156, mar. 2014.

. Currículo, conhecimento e transmissão cultural: contribuições para uma teorização pedagógica contemporânea. Cadernos de pesquisa, v. 46, n. 159, jan./mar. 2016.

TOMIO, Samira Alessandra. A Revista Nova Escola e o processo de construções sobre o livro didático. 2013. Dissertação (Mestrado em Educação) - Universidade de Blumenau, Centro de Ciências da Educação, Programa de Pós-Graduação em Educação, Blumenau, 2013.

VEIGA-NETO, Alfredo. Delírios avaliatórios: o currículo desvia para a direita ou um farol para o currículo. In: FAVACHO, André Márcio P.; PACHECO, José Augusto; SALES, Shirlei Rezende. Currículo: conhecimento e avaliação - divergências e tensões. Curitiba: CRV, 2013. p. 155-175.

Gubernamentalidad neoliberal: implicaciones para la educación. Educación y Pedagógia, v. 22, p. 213-235, 2010.

Recebido em: 20/3/2017

Aceito em: 14/6/2017 